\title{
Design and Development of Automatic Bending Machine
}

\author{
Shantanu Garad ${ }^{1}$, Sagar Ahire ${ }^{2}$, \\ Atharva Gaidhani ${ }^{3}$, Pratik Bagul ${ }^{4}$ \\ 1,2,3,4 Students, Department of Mechanical Engineering \\ N.D.M.V.P.'s. K.B.T. College of Engineering, \\ Nashik, India.
}

\author{
Dr. Amol Kakade 5 \\ ${ }^{5}$ Associate Professor, \\ Department of Mechanical Engineering \\ N.D.M.V.P.'s. K.B.T. College of Engineering, \\ Nashik, India.
}

\begin{abstract}
Presently, bending machines has tremendous use within the field of workplace. The bending machine is one among the foremost important machine in sheet work shop. It's primarily designed for bending. The bend has been made with the assistance of press which exerts large impact force on the work clamped on the die. Manual bending machine takes extra time and also take more efforts to bend the work piece. Hence, it takes longer time for production. There's lack of reproducibility, repeatability, and effectiveness. It also fails to satisfy customer satisfaction. So, our aim is that the bending machine is meant in such how that, it works automatically. The automation strategy, when implemented give rise to reduced cycle time, costs and improved product quality. Further probable benefits are increased output, ease of operation and incorporation of business systems. This bar bending machine replacement for manual machine and it's a semi-automatic one by using electrical motor, gear box etc., it simplify the manual work and economic wise by reducing the labor.
\end{abstract}

Keywords - Bending Machine, Production, Low cost, Automation.

\section{INTRODUCTION}

Automatic bending machine is operated by electrical means, where the worker requires for supplying the bars and operating the switches only. It is moveable type machine, so it can be carried anywhere. This Automatic bending machine is low power consumption. Electric bending machines are often utilized in the automotive, aerospace, construction, and ship building industries. Within the aerospace industry, precision is required and heavy work pieces got to be bent. This bending machines not only offer precision but are also more power-efficient than bending machines works on other mechanisms. In traditional method bending of straight reinforcement bar is completed with hand operated mechanism. Whole accuracy of bend is depends upon Skill \& experience of worker. There are machines works on pneumatic and hydraulic are also used for creating stirrups but those machine has major drawback of requirement of huge space for storage tank and compressor which makes machine heavy and steady. This project aims to bend the rod, metal strips at the required dimensions. Currently, metal rods, strips are bend manually, which suffers from many demerits like lack of accuracy, low productivity and resulting into severe fatigue within the operators. The project is based on the principle of automation. This automatic machine has significant advantages than the other machines. The manual bending process suffers from the various downsides. Workers not only exposing their hands to hours of tedious motion but also sometimes suffers internal injury to his body organ i.e. disorder carpal tunnel syndrome etc.

Our Bending machine is typically used for making I-Bolts to support various truss structures as well as electric rods and cell towers and it is also used to bend stirrups for fabrication purpose. Previously, this bending operations are carried with the help of pneumatic type of bending machine which experience lots of demerits like continuous adjustment of stirrups, lack of accuracy in final product. The power requirement of this pneumatic bending machine was also high. Due to its alternative parts maintenance cost also increased and this makes the firm to develop machine which replace this pneumatic one. So to avoid above listed drawbacks this was the reason and need behind Design and development of Automatic Bending Machine.

A Brief review of work has been carried out by many researchers for design and development of bending machine for several applications. Vadaliya Darshit et al. [1] described about Design and Analysis of Bar Bending Machine to achieve high productivity. Tawanda Mushiri et al. [2] analysed Design of an electrically powered bending machine. It has been made by considering a steel plate of width $80 \mathrm{~mm}$ and thickness $1 \mathrm{~mm}$. Layout of the machine and the configuration is decided based on this study. By means of the standard design procedure, various components of the machine is designed and the design details are shown in respective sections. C. Anbumeenakshi et al. [3] investigated about Design and Fabrication of Multi-rod Bending Machine. The multi rod bending machine is an electro hydraulic unit, where the electrical power supply causes the motor to run and the hydraulic power pack provides the necessary force that is required to bend the rods. A.D.Zope et al. [4] worked on Design and Development of Metal Bending Machine. They design and develop metal bending machine i.e. a sheet and tube roller by using hydraulic jack and rollers. P.N.Awachat et al. [5] investigated about Design and Analysis of Re-Bar Bending Machine. For portable machine, they are making rebar bending machine works on motor and microprocessor, which eliminates the need of storage tank or compressor. Pankaj Kumar Pandey et al. [6] illustrates about Design and fabrication of hydraulic bending machine which can bends a small sheet, shafts, pipes and tubes. Thokale Manoj et al.[7] worked on Design and fabrication of pneumatic bar bending machine. While analysing the stirrups making machine, it is observed that how much period is essential to make single piece of stirrup by effective working. 


\section{DESIGN AND DEVELOPMENT OF BENDING MACHINE}

According to customer's requirement, Machine is capable of producing accurate dimensions parts with less time. So development of machine begins with detailed review of parts and design of various components.

\section{A. Details of Parts}

Table 1 shows total list of parts with their material used in "Automatic Bending Machine".3D illustration of conceptual model of Automatic Bending Machine is shown in Figure 1.

\section{TABLE I. LIST OF PARTS}

\begin{tabular}{|l|l|l|l|}
\hline Sr. No. & \multicolumn{1}{|c|}{ Part Name } & \multicolumn{1}{c|}{ Material } & \multicolumn{1}{c|}{ Quantity } \\
\hline 1 & Base Frame & Mild Steel & 1 \\
\hline 2 & Side Frame & Mild Steel & 1 \\
\hline 3 & Shaft & Mild Steel (EN31) & 1 \\
\hline 4 & Handle & Mild Steel & 1 \\
\hline 5 & Bush & Mild Steel (EN31) & 1 \\
\hline 6 & Disc & Mild Steel & 1 \\
\hline 7 & Fasteners & - & 32 \\
\hline 8 & Studs & - & 8 \\
\hline
\end{tabular}

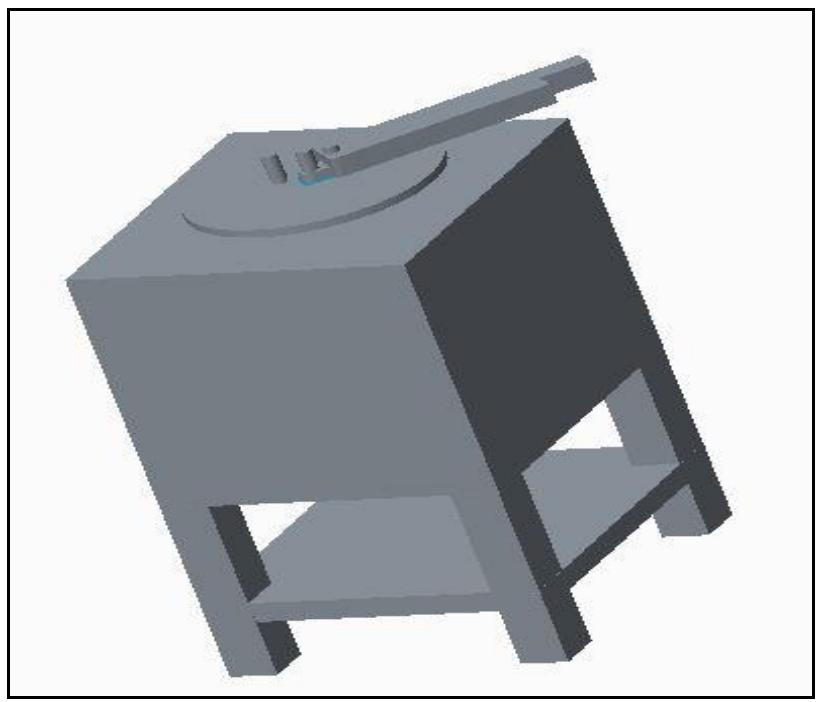

Fig.1.3D View of Conceptual Model

\section{B. Force Calculations}

To start with the design process we consider various material properties such as yield strength, ultimate tensile strength, etc. Figure 2 shows Forces acts on "Automatic Bending Machine" with proper dimensions.

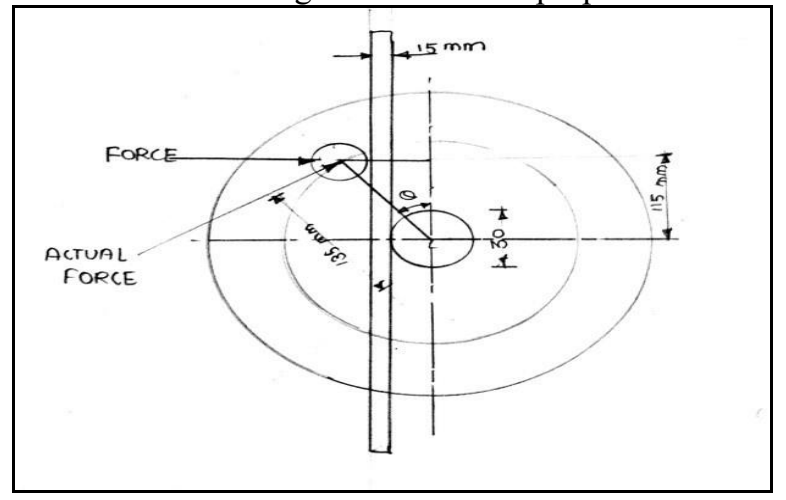

Fig. 2. Dimensions of Disc [1]
Consider,

$\mathrm{M}=$ Moment about neutral axis

$\sigma_{\mathrm{b}}=$ Bending stress

$\mathrm{y}=$ Perpendicular distance to neutral axis

$\mathrm{I}=$ Moment of inertia

$\frac{M}{I}=\frac{\sigma}{\mathrm{Y}}$

$I=\frac{\pi}{64} * D^{4}$

$\mathrm{D}=15 \mathrm{~mm}$ of the bar

$I=\frac{\pi}{64} *(15)^{4}$

$=2485 \mathrm{~mm}^{4}$

For S.I.grade 20 bar yield strength given as,

$\mathrm{S}_{\mathrm{yt}}=271 \mathrm{~N} / \mathrm{mm}^{2}$

Let factor of safety is 3

$Y=\frac{D}{2}$

$=15 / 2$

$=7.5 \mathrm{~mm}$

$\sigma_{\mathrm{b}}=\mathrm{S}_{\mathrm{yt}} / 3$

$=271 / 3$

$=90.33 \mathrm{~N} / \mathrm{mm}^{2}$

$M=\frac{I}{Y} * \sigma_{\mathrm{b}} \quad[9]$

$=(2485 * 90.33) / 5$

$=44.89 \mathrm{KN}-\mathrm{mm}$

$\mathrm{L}=$ length of bar from actual bend

$\mathrm{L}=450 \mathrm{~mm}$

Let assume simply supported beam with point load, which acting center position of beam.

$\mathrm{W}=\mathrm{F}=$ Force

For simply supported beam,

$M=W * \frac{L}{4}$

So,

$M=W * \frac{L}{4}$

$=(4 * 44895.501) / 450$

$=399.07 \mathrm{~N}$

$\sim 400 \mathrm{~N}$

Above force acts perpendicular to bar so, we need to calculate actual force with its direction.

From figure 2,

$\cos \theta=\frac{\text { adjacent side }}{\text { hypoteneous }}$

$\cos \theta=\frac{115}{135}$

$\Theta=30^{\circ}$

$\mathrm{F}_{\mathrm{t}}=$ Actual force

$\cos 30=\frac{F}{F t}$

$\operatorname{Cos} 30=400 / \mathrm{F}_{\mathrm{T}}$

$\mathrm{F}_{\mathrm{T}}=461.880 \mathrm{~N}$

$\sim 465 \mathrm{~N}$

Therefore torque is given by,

$\mathrm{T}=\mathrm{F}_{\mathrm{t}} * \mathrm{R}$

$=\left(465^{*} 135\right) / 1000$

$=62.77 \mathrm{~N}-\mathrm{m}$ 
$P=\frac{2 \pi N T}{60}$

$P=2 \pi * 95 * \frac{62.77}{60}$

$=624.45 \mathrm{~W}$

$=0.624 \mathrm{KW}$.

\section{Selection of Belt from Manufacturer Catalogue}

In practice, the designer has to select a V-belt which is shown in Figure 3 from the catalogue of the manufacturer.

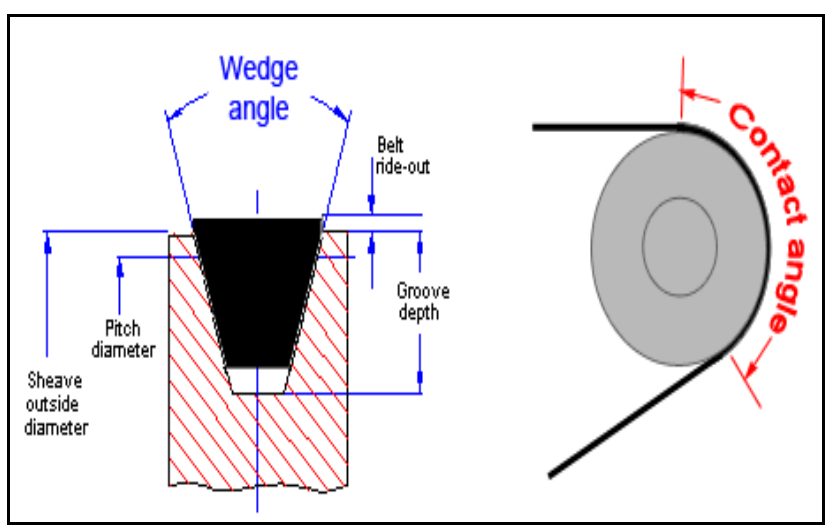

Fig. 3. V-Belt Cross-section [8]

The basic procedure for the selection of V-belts consists of the following steps:

- $\quad$ Determine the correction factor according to service ( $F a$ ) from Table 13.15(V. B. Bhandari). It depends upon the type of driving unit, the type of driven machine and the operational hours per day.

- $\quad$ Calculate the design power by the following way,

Design power $=F a($ transmitted power $)[9]$

$=1.1 * 0.624$

$=0.6864 \mathrm{KW}$

- $\quad$ Plot a point with design power as $X$ coordinate and input speed as $Y$ co-ordinate in Fig. 13.24 (V. B. Bhandari). The location of this point decides the type of cross-section of the belt. In a borderline case, such as the point located on the borderline of cross-sections $B$ and $C$, alternative calculations are made to find out the best cross-section.

So, cross section ' $A$ ' is selected.

- Determine the recommended pitch diameter of the smaller pulley from Table 13.12(V. B. Bhandari). It depends upon the cross-section of the belt. Calculate the pitch diameter of the bigger pulley by the following relationship:

$$
\begin{aligned}
\mathrm{d} & =125 \mathrm{~mm} \\
\mathrm{D} & =125^{*}(1440 / 1225) \\
& =146.93 \mathrm{~mm} \\
\sim & 150 \mathrm{~mm}
\end{aligned}
$$$$
D=d \text { (Input speed /output speed })[9]
$$

The above values of $D$ and $d$ are compared with the preferred pitch diameters given in Table 13.13(V. B. Bhandari).. In case of non-standard value, the nearest values of $d$ and $D$ should be

taken from Table 13.13.(V. B. Bhandari).

- $\quad$ Determine the pitch length of belt $L$ by the following relationship,

$$
\begin{aligned}
& L=2 C+\frac{\pi(D+d)}{2}+\frac{(D-d)^{2}}{4 C} \text { [9] } \\
& \mathrm{C}=550 \mathrm{~mm} \\
& \mathrm{~L}=1532.25 \mathrm{~mm} \\
& \sim 1550 \mathrm{~mm}(\mathrm{~A})
\end{aligned}
$$

- $\quad$ Compare the above value of $L$ with the preferred pitch length $L$ in Table 13.14(V. B. Bhandari). In case of a non-standard value, the nearest value of pitch length from Table 13.14 should be taken.

$$
\mathrm{L}=1550 \mathrm{~mm}
$$

- $\quad$ Find out the correct centre distance $C$ by substituting the above value of $L$ in the following equation:

$$
L=2 C+\frac{\pi(D+d)}{2}+\frac{(D-d)^{2}}{4 C}[9]
$$

It is a quadratic equation in $C$.

$\mathrm{C}=342.57 \mathrm{~mm}$

- $\quad$ Determine the correction factor $(F c)$ for belt pitch length from Table 13.21(V. B. Bhandari). It depends upon the type of cross-section and the pitch length of the belt.

$$
\mathrm{Fc}=0.98
$$

- $\quad$ Calculate the arc of contact for the smaller pulley by the following relationship:

$$
\begin{aligned}
& \alpha=180-2 \operatorname{Sin}^{-1} * \frac{D-d}{2 C}[9] \\
& \alpha=177^{\circ}
\end{aligned}
$$

Determine the correction factor $(F d)$ for the arc of contact from Table 13.22(V. B. Bhandari). It is not advisable to use an arc of contact less than $120^{\circ}$ for V-belt drive. Therefore, the minimum arc of contact should be $120^{\circ}$.

$$
F d=0.99
$$

- Depending upon the type of cross-section, refer to the respective table from Table $13.16-13.20$ (V. B. Bhandari), the power rating $(P r)$ of single $\mathrm{V}$-belt can be find out.

$$
\operatorname{Pr}=2.24
$$

- $\quad$ The last step in the selection procedure is to find out the number of belts.

$$
\begin{aligned}
& \text { No. of bolts }=P * \frac{F a}{P r * F c * F d}[9] \\
& =(0.624 * 1.1) /(2.24 * 0.98 * 0.99) \\
& =0.312 \\
& \sim 1 \text { belt. }
\end{aligned}
$$

\section{Chain Drive Power}

From V. B. Bhandari, Design of Machine Elements, following values can be noted.

$\mathrm{K}_{\mathrm{s}}=1.3$
$\mathrm{~K}_{1}=1.7$
$\mathrm{~K}_{2}=1$

$(\mathrm{KW})_{\text {rating }}=P * \frac{K s}{K 1} * K 2$ [9]

$=0.4771 \mathrm{KW}$

Power rating of chain is $0.4771 \mathrm{KW}$.

\section{TRIALS AND DISCUSSION}

The trials were conducted on newly developed automatic bending machine for various components. The time and speed were recorded. Therefore Table 2 shows results after the trails on various types of parts conducted on "Automatic Bending Machine". Figure 4 shows the time required for bending operations for different dimension parts. 
TABLE II COMPONENTS AND TIME FOR BENDING OPERATION

\begin{tabular}{|c|c|c|c|c|c|c|}
\hline $\begin{array}{l}\text { Sr. } \\
\text { No }\end{array}$ & $\begin{array}{l}\text { Parts } \\
\text { Name }\end{array}$ & \multicolumn{2}{|c|}{ Dimensions } & $\begin{array}{l}\text { Time } \\
\text { (Min) }\end{array}$ & $\begin{array}{l}\text { Speed } \\
(\mathbf{r p m})\end{array}$ & $\begin{array}{c}\text { Mode of } \\
\text { Drive }\end{array}$ \\
\hline \multirow{5}{*}{1} & \multirow{5}{*}{$\begin{array}{l}\text { M.S. } \\
\text { Rod }\end{array}$} & \multicolumn{2}{|c|}{ Rod Diameter } & - & \multirow{5}{*}{18} & \multirow{5}{*}{$\begin{array}{l}\text { Automatic } \\
\text { Drive }\end{array}$} \\
\hline & & \multicolumn{2}{|l|}{$\varnothing 10 \mathrm{~mm}$} & 2 & & \\
\hline & & \multicolumn{2}{|l|}{$\emptyset 12 \mathrm{~mm}$} & 2 & & \\
\hline & & \multirow{2}{*}{\multicolumn{2}{|c|}{$\varnothing 14 \mathrm{~mm}$}} & 2.5 & & \\
\hline & & & & 3 & & \\
\hline \multirow{3}{*}{2} & \multirow{3}{*}{$\begin{array}{l}\text { M.S. } \\
\text { Tube }\end{array}$} & $\begin{array}{l}\text { Nominal } \\
\text { Bore }\end{array}$ & $\begin{array}{l}\text { Outside } \\
\text { Diameter }\end{array}$ & - & \multirow{3}{*}{18} & \multirow{3}{*}{$\begin{array}{l}\text { Automatic } \\
\text { Drive }\end{array}$} \\
\hline & & $3 \mathrm{~mm}$ & $10.32 \mathrm{~mm}$ & 1.5 & & \\
\hline & & $6 \mathrm{~mm}$ & $13.49 \mathrm{~mm}$ & 2 & & \\
\hline \multirow{4}{*}{3} & & Width & Thickness & - & \multirow{4}{*}{18} & \multirow{4}{*}{$\begin{array}{l}\text { Automatic } \\
\text { Drive }\end{array}$} \\
\hline & & $25 \mathrm{~mm}$ & $10 \mathrm{~mm}$ & 1 & & \\
\hline & M.S. & $25 \mathrm{~mm}$ & $12 \mathrm{~mm}$ & 1.5 & & \\
\hline & Flats & $32 \mathrm{~mm}$ & $10 \mathrm{~mm}$ & 1 & & \\
\hline
\end{tabular}

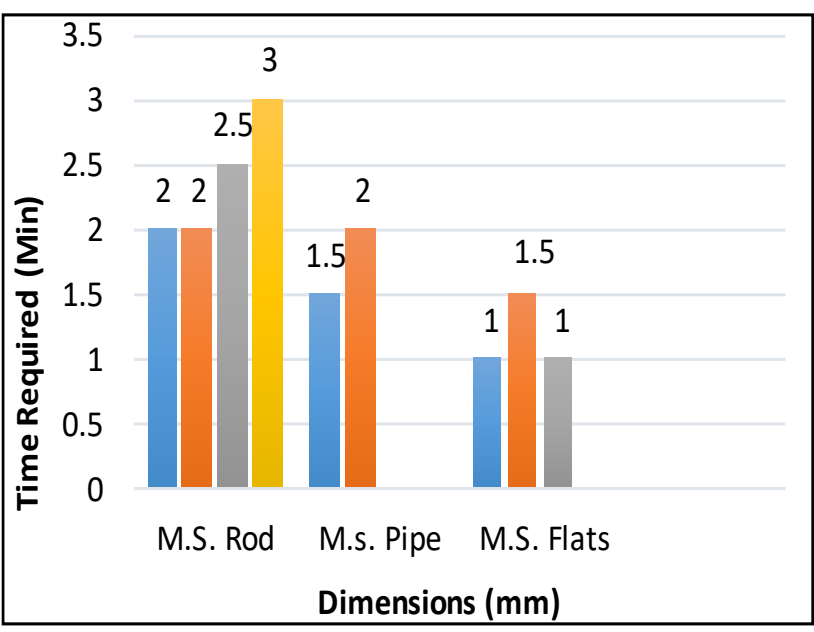

Fig. 4. Time required for various elements for bending operation

Meanwhile testing the components making machine it can be observed that how much time is needed to complete one piece of final product in operative condition. The thorough explanation is given below:

The data provides insight into the relationship between required time to bend part in expected profile and dimensions of material which is to be bend. Loading and unloading of one piece almost takes only 5-8 seconds. Average time required for complete bending of one component is about 11.5 Minutes. Taking into consideration machine workplace efficiency which is nothing but the collaboration of human worker with machine, it is comfortable to operate such machine because the total mechanism is automatically controlled.

Again loading and unloading is not difficult since not any alternate tooling is used, it is very simple structure. By considering that, every component require total time of 1.5 Minutes, so in one hour 40 final products can be made. Hence after effective working of 8 hours we can produce more than 320 components. The result of trial suggest that force required for bending is not constant for every component. For example; Force required to bend rod is diverse from the force required to bend tubes or strips.

\section{CONCLUSIONS}

The most important outcomes of present research have been concisely summarized as follows:

- The present methods for bending rod, pipe and metal strips are of great significant for modern job order type production workshops. The situation where the workshop owner can't afford different machines for different application such as for pipe bending. So this machine is become an option for such type of workshops.

- "Automatic Bending Machine" is affordable to them at optimum cost and it will able to bend both rod as well as pipe. It also helps to reduce shop floor area as it can assemble and dismantle easily whenever required.

- After observing the results obtained from machine study we are able to know that cost required for this machine is much less than other machines available in the market.

- This machine also has the advantages of less cost, multi functioning, easy assembly and dismantling according to need, optimum accuracy, easy to use, no slipping action of pipe etc. in short this is very useful for small scale workshops having less investment.

\section{REFERENCES}

[1] Vadaliya Darshit, Thummar Kuldip, Vala Bhargav, Unal Mohmmadaamr, Tank Kishan, Prof. Nikunj Gevariya "Design and Analysis of Bar-Bending Machine" International Research Journal of Engineering and Technology (IRJET) Volume: 05 Issue: 04, 172-175(2018).

[2] Tawanda Mushiri "Design of an electrically powered bending machine: Case of Zimbabwe" Proceedings of the International Conference on Industrial Engineering and Operations Management RabatApril 11-13,1739-1751 (2017).

[3] C. Anbumeenakshi, M. R. Thansekhar, Thanamani.M, Santhoshkumar R, Parivallal.S, Senthilkumar.K "Designand Fabrication of Multirod Bending Machine "International Journal of Current Engineering and Scientific Research (ijcesr) volume-5, issue-1, 20-24 (2018).

[4] A. D. Zope, R. R. Deshmukh, D.R. Mete, V. S. Mane "Review Paper on Design and Development of Metal Bending Machine" IOSR Journal of Mechanical and Civil Engineering, 46-48 (2017).

[5] P. N. Awachat, Ghulam Dastgeer, Aman Gohite "Design and Analysis of Re-bar Bending Machine", International Journal of Innovative Research in Advanced Engineering, vol- 2,103105(2015).

[6] Pankaj Kumar Pandey, Arjun NumarNishad, Alok Mishra, Dinesh Kumar Gupta, Faisal Ali Ansari , "Design and Fabrication of Hydraulic Bending Machine" International Conference on Recent Innovation in Science and Engineering, 485-490(2018).

[7] Thokale Manoj, Kothwal Satish, Kotkar Rahul, More Suyog, Pawase Mahesh, "Design And Fabrication of Pneumatic Bar Bending Machine", International Research Journal of Engineering and Technology,Vol-04,Issue- 03, 1403-1406(2017).

[8] https://www.google.com/url?sa=i\&source=images \&cd=\&ved=2ah UKEwjO9ITfra_mAhXd9nMBHSZYA8sQjRx6BAgBEAQ\&url=h ttp $\% 3 \mathrm{~A} \% 2 \mathrm{~F} \% 2 \mathrm{Fwww}$. learneasy.info\%2FMDME\%2FMEMmods \%2FMEM30009A\%2Fshaft_drives\%2Fshaft_drives.html\&psig=A OvVaw0wvxjWaB_ Twvcfas_hPi4z\&ust=1576214223424044 ( v belt).

[9] V. B. Bhandari - Design of Machine Elements Third Edition, Tata McGraw Hill Publishing Company (1994). 